\title{
HUBUNGAN KERAPATAN LAMUN (SEAGRASS) DENGAN KELIMPAHAN TERIPANG (HOLOTHURIA) DI PANTAI ALANG-ALANG TAMAN NASIONAL KARIMUNJAWA
}

\author{
Seagrass Density Relation (Seagrass) with Abundance of Sea Cucumber (Holothuria) at Alang-Alang Beach \\ Karimunjawa National Park.
}

\section{Mafi Ristina, Bambang Sulardiono*), Anhar Solichin}

Program Studi Manajemen Sumberdaya Perairan, Departemen Sumberdaya Akuatik

Fakultas Perikanan dan Ilmu Kelautan, Universitas Diponegoro

J1. Prof. Soedarto, SH, Tembalang, Semarang, Jawa Tengah, Indonesia - 50275, Telp/Fax. +6224 7474698

Email: mafiristina25@yahoo.co.id

\begin{abstract}
ABSTRAK
Pantai Alang-alang terletak di Taman Nasional Karimunjawa yang memiliki ekosistem lamun dengan cukup baik. Banyak biota yang berasosiasi dengan lamun, salah satunya teripang yang merupakan unsur kekayaan keanekaragaman hayati laut. Tingginya harga pasar dan manfaat yang begitu besar bagi manusia, membuat permintaan komoditas tersebut meningkat dari waktu ke waktu sehingga mengancam kelestarian jenis tersebut di habitatnya. Penelitian ini bertujuan untuk mengetahui kerapatan lamun, kelimpahan teripang, dan mengetahui hubungan antara kerapatan lamun dengan kelimpahan teripang di Pantai Alang-alang, Karimunjawa. Pelaksanaan penelitian dilakukan pada bulan Mei 2018 di perairan Pantai Alang-alang, Karimunjawa. Metode yang digunakan dalam penelitian yaitu metode observasi dengan metode samplingnya random sampling. Pengambilan sampel teripang dilakukan pada ketiga stasiun lamun dengan kerapatan jarang, sedang, dan padat. Penghitungan pemetaan lamun dan kelimpahan teripang menggunakan kuadran $1 \mathrm{~m}$ x $1 \mathrm{~m}$ dan dilakukan sebanyak 3 kali pengulangan. Hasil penelitian menunjukkan terdapat 4 jenis lamun yaitu Enhallus acoroides, Cymodoceae serulata, Thalasia hemprichii, dan Cymodoceae rotundata. Jumlah tegakan lamun pada kerapatan jarang 5378 tegakkan/80 ${ }^{2}$, kerapatan sedang 13564 tegakkan/80m², dan kerapatan padat 28632 tegakkan $/ 80 \mathrm{~m}^{2}$. Teripang yang didapatkan di Pantai Alang-alang yaitu sebanyak 1 spesies pada kerapatan padat sejumlah $48 \mathrm{ind} / 80 \mathrm{~m}^{2}$, kerapatan sedang $39 \mathrm{ind} / 80 \mathrm{~m}^{2}$, dan pada kerapatan jarang 16 ind $/ 80 \mathrm{~m}^{2}$. Hasil analisa statistika kerapatan lamun dengan kelimpahan teripang terdapat korelasi $r=0,914$, menunjukan korelasi erat sehingga semakin tinggi kerapatan lamun akan diikuti oleh melimpahnya teripang.
\end{abstract}

Kata Kunci: Teripang; Lamun; Hubungan; Pantai Alang-alang; Karimunjawa

ABSTRACT
Alang-alang Beach is located in Karimunjawa National Park which has good seagrass ecosystem. Many biota associated with seagrass, one of them is Holothuria which is an element of marine biodiversity richness. The high market price and the enormous benefits for humans, make the demand for these commodities increase over time, thus threatening the sustainability of the species in their habitat. This study aims to determine the density of seagrass, to know the abundance of Holothuria, and to know the relationship between the density of sea grass with the abundance of Holothuria in Alang-alang Beach, Karimunjawa. The research was conducted in May 2018 in the waters of AlangAlang Beach, Karimunjawa. The method used in the research is the method of observation by the method of sampling random sampling. Sampling of sea cucumbers was done on three seagrass stations with rare density, medium, and solid. Calculation of seagrass mapping and abundance of Holothuria using quadrant $1 \mathrm{~m} \times 1 \mathrm{~m}$ and done as much as 3 times repetition. The results showed that there were 4 types of seagrass: Enhallus acoroides, Cymodoceae serulata, Thalasia hemprichii, and Cymodoceae rotundata. The amount of seagrass standing at rare density 5378 stands $/ 80 \mathrm{~m}^{2}$, medium density 13564 stands / 80 ${ }^{2}$, and solid density 28632 stands / 80m². Holothuria are obtained in Alang-alang Beach that is 1 species in solid density of 48 ind / $80 \mathrm{~m}^{2}$, medium density 39 ind $/ 80 \mathrm{~m}^{2}$, and at rare density 16 ind / $80 \mathrm{~m}^{2}$. The result of statistical analysis of seagrass density with the abundance of Holothuria is correlation $r=0,914$, showing the correlation closely so that the higher density of sea grass will be followed by abundance of sea cucumber.

Keywords: Sea cucumber; Seagrass; Relationship; Alang-alang beach; Karimunjawa

\section{PENDAHULUAN}

Wilayah pesisir didefinisikan sebagai wilayah daratan yang berbatasan dengan laut, batas di daratan meliputi daerah-daerah yang tergenang air yang masih dipengaruhi oleh proses-proses laut seperti pasang surut, angin laut dan intrusi garam, sedangkan batas di laut ialah daerah-daerah yang dipengaruhi oleh proses-proses alami di daratan seperti 
sedimentasi dan mengalirnya air tawar kelaut, serta daerah-daerah laut yang dipengaruhi dari kegiatan-kegiatan manusia di daratan. Adanya berbagai aktifitas manusia di sekitar perairan tersebut dapat merusak ekosistem pada perairan (Bengen, 2001). Salah satu ekosistem di perairan pantai tersebut adalah padang lamun yang mempunyai fungsi sebagai tempat untuk mencari makan, berpijah, sebagai daerah asuhan serta perlindungan dari berbagai jenis biota laut (Taurusman, 2009). Salah satu unsur kekayaan keanekaragaman hayati laut adalah teripang. Salah satu pantai di Karimunjawa yang memiliki habitat padang lamun dan terumbu karang yang masih baik adalah Pantai Alang-alang. Pantai tersebut merupakan pemukiman dimana pada pantai tersebut masih banyak padang lamun yang masih baik kondisinya. Tujuan dari penelitian ini adalah untuk mengetahui kerapatan lamun, kelimpahan teripang dan hubungan antara kerapatan lamun dengan kelimpahan teripang di Pantai Alang-alang, Karimunjawa yang dilaksanakan pada bulan Mei 2018.

\section{MATERI DAN METODE PENELITIAN}

Materi yang digunakan dalam penelitian ini adalah teripang dan jenis lamun yang ditemukan di padang lamun di Pantai Alang-alang, Karimunjawa. Metode penelitian yang digunakan dalam penelitian ini adalah metode observasi. Metode observasi yaitu metode yang dilakukan dengan pengamatan dan pencatatan secara sistematis mengenai kejadian-kejadian yang diselidiki dalam suatu penelitian dan hasilnya diharapkan dapat menggambarkan sifat populasi dari suatu obyek (Sudjana, 2002). Dalam penelitian ini, kejadian yang diselidiki adalah kerapatan lamun dan kelimpahan teripang yang berada di perairan Pantai Alang-alang. Penelitian ini dilakukan di Pantai Alang-alang karena pada daerah tersebut masih terdapat padang lamun yang kondisinya bagus dan bervariasi jenisnya. Langkah - langkah dalam memetakan penghitungan kerapatan lamun yang pertama yaitu melakukan plotting menggunakan GPS pada lokasi. Hal yang dilakukan selanjutnya yaitu penarikan garis transek dilakukan sejajar dan tegak lurus garis pantai dimulai dari batas awal terdapat lamun hingga ujung batas keberadaan lamun untuk menentukan lokasi pemetaan. Penghitungan tegakan lamun dimulai dari adanya tumbuhan lamun 100 meter kearah laut, dan sejajar garis pantai sepanjang 200 meter. Sampling pemetaan kerapatan lamun dilakukan dengan meletakkan kuadran 1x1m untuk menandai bahwa daerah tersebut yang akan dilakukan perhitungan kerapatan. Penentuan lokasi dibedakan menjadi 3 yaitu lamun dengan kerapatan padat, sedang, dan jarang mengacu pada Widyorini et al., (2012), untuk kerapatan lamun yaitu kerapatan jarang jumlah individu dibawah 106 tegakan/ $\mathrm{m}^{2}$. kerapatan sedang jumlah individu berkisar antara 244 tegakan/ $\mathrm{m}^{2}$ dan kerapatan padat jumlah individu diatas 355 tegakan/ $\mathrm{m}^{2}$. Penghitungan lamun dilakukan sebanyak 3 kali pengulangan di setiap stasiun.

Sampling untuk pengambilan data teripang dilakukan dengan cara menangkap jenis teripang yang berada di sekitar garis transek. Selain itu juga melakukan pengambilan gambar dengan menggunakan kamera underwater. Data parameter lingkungan yang diukur pada saat penelitian adalah kedalaman, suhu, arus, salinitas dan $\mathrm{pH}$. Pengambilan data dilakukan secara insitu, yaitu pengambilan data secara langsung di lapangan pada saat penelitian. Metode analisis data yang digunakan yaitu:

\section{Kelimpahan relatif}

Untuk menentukan jumlah individu suatu spesies teripang terhadap jumlah total individu teripang yang terdapat di lokasi sampling digunakan Kelimpahan Relatif (Odum, 1971):

Keterangan:

$$
\mathrm{KR}=\mathrm{Pi} \times 100 \%
$$

KR = Kelimpahan Relatif

$\mathrm{Pi}=\frac{n i}{N}$ (peluang spesies i dari total individu)

\section{Indeks keanekaragaman} 2003), yaitu :

Keanekaragaman jenis lamun di hitung menggunakan Indeks Keanekaragaman Shannon - Weaner (Dahuri,

Keterangan:

$$
H^{\prime}=-\sum_{n i=1}^{\mathrm{s}} \mathrm{pi} \ln \mathrm{pi}
$$

$\mathrm{H}^{\prime} \quad=$ Indeks Keanekaragaman Shannon-Weaner

$\mathrm{Pi} \quad=\frac{n i}{N}($ peluang spesies i dari total individu $)$

$\mathrm{ni}=$ Jumlah individu dari suatu jenis ke-i

$\mathrm{N}=$ Jumlah total individu seluruh jenis

Kriteria dari indeks keanekaragaman ditentukan berdasarkan nilai yang didapat:

$\mathrm{H}^{\prime}<1 \quad=$ Keanekaragaman rendah

$1<\mathrm{H}^{\prime}<3 \quad=$ Keanekaragaman sedang

$\mathrm{H}^{\prime}>3 \quad=$ Keanekaragaman tinggi 


\section{Indeks keseragaman}

Indeks Keseragaman jenis di hitung dengan menggunakan rumus Odum (1971):

Keterangan:

$$
e=\frac{H^{\prime}}{H \max }
$$

$$
\begin{array}{ll}
\mathrm{e} & =\text { Indeks keseragaman } \\
\mathrm{H}^{\prime} & =\text { Indeks Keanekaragaman } \\
\mathrm{Hmax} & =\text { Log } \mathrm{S}
\end{array}
$$

Nilai indeks keseragaman berkisar antara $0-1$, dengan kategori sebagai berikut:

$$
\begin{array}{ll}
\mathrm{e}<0,4 & =\text { Keseragaman kecil } \\
0,4<\mathrm{e}<0,6 & =\text { Keseragaman sedang } \\
\mathrm{e}>0,6 & =\text { Keseragaman besar }
\end{array}
$$

\section{HASIL DAN PEMBAHASAN}

Taman Nasional Karimunjawa dengan luas daratan \pm 1.500 hektar dan perairan \pm 110.000 hektar dan memiliki 27 pulau. Pantai Alang-alang merupakan salah satu pantai yang berada di Karimunjawa Jepara, yang memiliki pemukim dengan kondisi tanahnya yang berpasir sehingga menyulitkan untuk pertanian, maka sebagian besar mata pencaharian penduduknya adalah nelayan. Pantai Alang-alang terletak di Dusun Alang-alang yang jaraknya $\pm 4 \mathrm{~km}$ dari alun-alun Karimunjawa. Pantai Alang-alang yang terletak di Dusun Alang-alang ini memiliki keindahan tersendiri yaitu memiliki pasir berwarna putih dan airnya yang jernih berwarna biru. Pantai Alang-alang masih memiliki lamun yang cukup baik dan berbagai biota seperti teripang dan lain sebagainya. Penentuan lokasi penelitian dilakukan dengan perbedaan kerapatan lamun padat, sedang dan jarang. Kerapatan lamun padat 05॰50'18.8" S dan 110॰25'18.9" E, kerapatan lamun sedang $05 \circ 50$ '27" S dan 110॰25'18.54" E, sedangkan kerapatan lamun jarang yaitu 05॰50'18.28” S dan 110॰25'18.26" E.

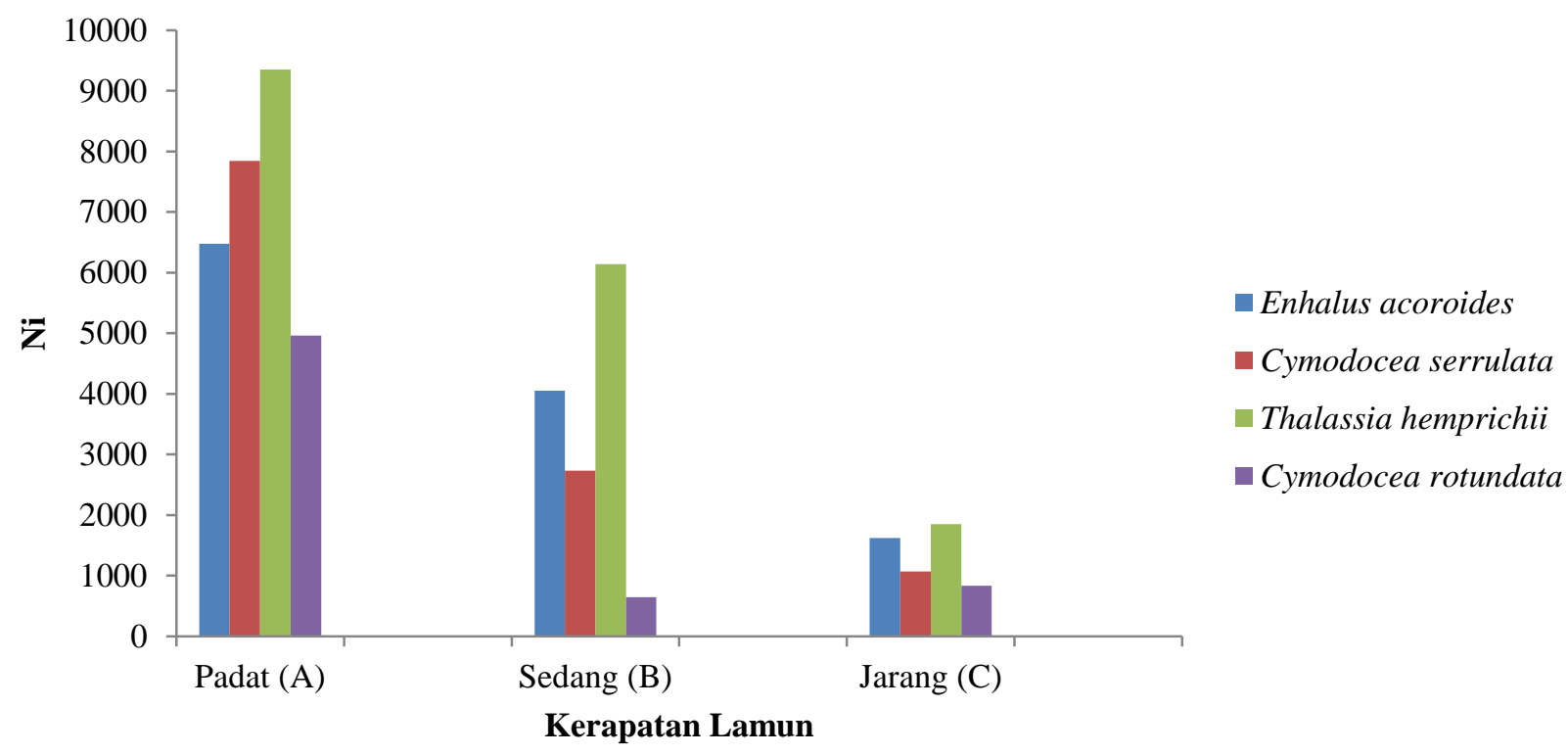

Gambar 1. Kerapatan dan Komposisi Lamun di Pantai Alang-alang

Berdasarkan Gambar 1 diatas dapat dilihat bahwa ditemukan empat jenis lamun yang tumbuh di perairan Pantai Alang-alang. Keempat jenis yang didapatkan tersebut yaitu Enhallus acoroides, Cymodoceae serulata, Thalasia hemprichii, dan Cymodoceae rotundata. Lamun pada kerapatan padat,dengan jumlah 28632 tegakan/ $80 \mathrm{~m}^{2}$, terdapat Thalasia hemprichii yang merupakan spesies paling banyak ditemui yaitu 9354 tegakan/ $80 \mathrm{~m}^{2}$. Kerapatan lamun sedang yang memiliki jumlah 13564 tegakan/ 80 $\mathrm{m}^{2}$, jenis yang sering dijumpai adalah Thalasia hemprichii dengan jumlah 6137 tegakan $/ 75 \mathrm{~m}^{2}$, sedangkan pada lamun kerapatan jarang yang memiliki jumlah 5378 tegakan/ 80m ${ }^{2}$, jenis yang paling banyak dijumpai yaitu jenis Thalassia hemprichii sejumlah 1848 tegakan $/ 80 \mathrm{~m}^{2}$. Jenis lamun yang paling mendominasi pada kerapatan padat, sedang dan jarang yaitu jenis Thalassia hemprichii, karena pada dasarnya jenis lamun Thalassia hemprichii memiliki strategi adaptasi yang paling baik diantara jenis lamun lainnya. Menurut Romimohtarto dan Juwana (2001), menyatakan bahwa T. hemprichii memiliki strategi adaptasi yang baik terhadap lingkungannya dimana tumbuhan tersebut memiliki perakaran serabut dengan mikrozoma akar aerobic sehingga mampu berkoloni lebih lebat di habitat dangkal dibandingkan dengan lamun jenis lainnya. Jenis lamun.

Menurut Duarte (1991) dalam Vermaat et al.. (1995) melakukan analisis komparatif terhadap hubungan jenis lamun yang berbeda ukurannya dengan dinamika pertumbuhan lamun. Jenis lamun dengan ukuran yang besar akan 
mengalami masa hidup yang panjang namun pertumbuhan yang lambat, sedangkan jenis lamun dengan ukuran yang kecil memiliki masa hidup yang pendek namun memiliki pertumbuhan yang cepat.

Hasil perhitungan nilai indeks keanekaragaman ( $\left.\mathrm{H}^{\prime}\right)$ dan keseragaman (e) lamun di Pantai Alang-alang dapat dilihat dalam Tabel 1 berikut.

Tabel 1. Indeks Keanekaragaman dan Keseragaman Lamun di Pantai Alang-alang

\begin{tabular}{|c|c|c|c|}
\hline & Padat (A) & Sedang (B) & Jarang $(\mathrm{C})$ \\
\hline Indeks keanekaragam (H') & 1,358 & 1,186 & 1,338 \\
\hline Indeks keseragaman (e) & 0,980 & 0,856 & 0,965 \\
\hline
\end{tabular}

Berdasarkan Tabel 1 tersebut, bahwa indeks keanekaragaman ( $\left.\mathrm{H}^{\prime}\right)$ pada padang lamun kerapatan padat, sedang dan jarang nilai indeks keanekaragaman $\left(\mathrm{H}^{\prime}\right)$ yang paling kecil nilainya yaitu pada kerapatan sedang yang memiliki nilai sebesar 1,186, sedangkan pada kerapatan padat dan jarang memiliki nilai yang hampir sama. Nilai indeks keanekaragaman pada ketiga stasiun menunjukkan nilai $\mathrm{H}^{\prime}<2$ yang menandakan bahwa kondisi perairan tergolong kurang baik. Menurut indeks keanekaragaman Shanon-Wiener (Dahuri, 2003), dimana $1<\mathrm{H}^{\prime} \leq 3$ maka keanekaragaman sedang. Tinggi rendahnya nilai indeks keanekaragaman jenis dapat disebabkan oleh berbagai faktor antara lain jumlah jenis atau individu yang didapat, adanya beberapa jenis yang ditemukan dalam jumlah yang lebih melimpah daripada jenis lainnya, kondisi homogenitas substrat, kondisi dari ekosietem lamun sebagai habitat dari fauna perairan (Yanu, 2011).

Nilai indeks keseragaman pada kerapatan lamun padat, sedang, dan jarang berturut-turut didapatkan nilai sebesar 0.980, 0.856 dan 0.965 yang selisih nilainya tidak jauh. Nilai indeks keseragaman di ketiga lokasi tersebut mempunyai keseragaman yang besar karena lebih dari 0.6, sehingga dapat menandakan bahwa kelimpahan jenis dapat dikatakan sama pada ketiga lokasi kerapatan tersebut dan cenderung tidak ada jenis lamun yang mendominasi (Wilhm, 1986).

Jenis teripang yang ditemukan di perairan Pantai Alang-alang dapat dilihat pada Gambar 2 berikut.

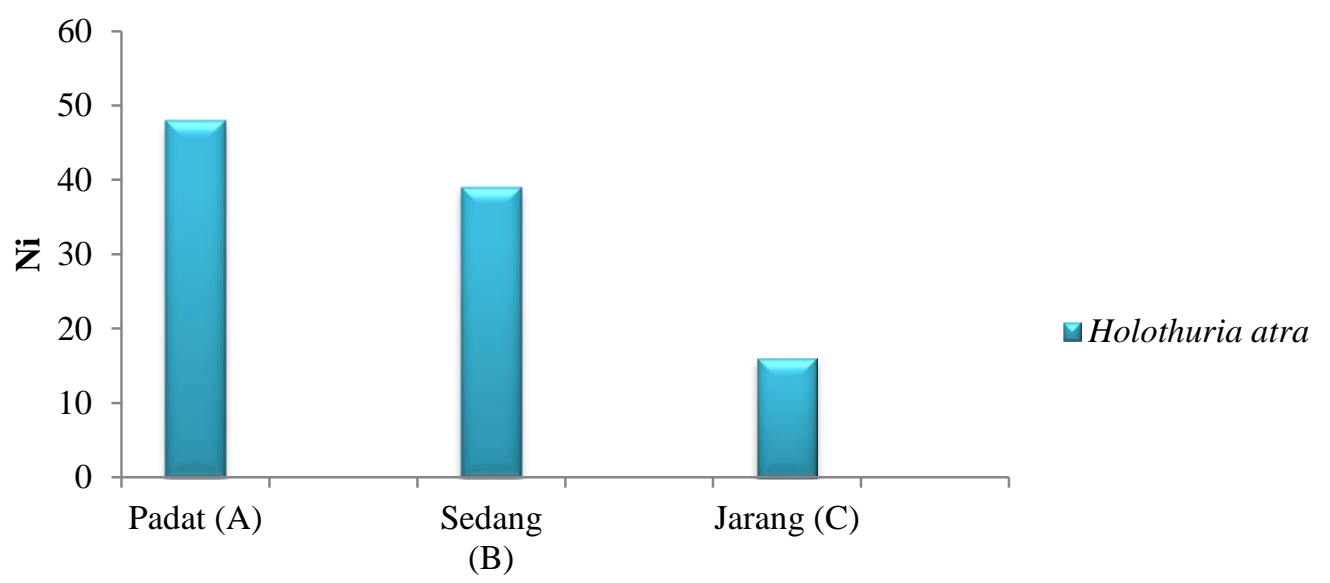

Kerapatan Lamun

Gambar 2. Jumlah Individu Teripang di Pantai Alang-alang

Berdasarkan Gambar 2 dapat dilihat bahwa teripang yang ditemukan yang paling sedikit jumlahnya yaitu pada kerapatan jarang, sedangkan teripang yang paling banyak ditemukan yaitu pada kerapatan padat. Jenis teripang yang ditemukan pada kerapatan lamun padat, sedang dan jarang yaitu Holothuria atra, karena pada umumnya jenis teripang Holothuria atra menyukai daerah yang bersubtrat pasir dan ditumbuhi oleh lamun. Hal ini diperkuat oleh Radjab (2001) dalam Haryasakti (2011), bahwa sebagian besar teripang menyukai daerah bersubtrat pasir dan ditumbuhi lamun seperti jenis Holothuria membenamkan diri lumpur atau pasir yang banyak ditumbuhi lamun. Teripang menyukai tempat yang berpasir dan ditumbuhi lamun selain karena di daerah padang lamun merupakan daerah yang sangat produktif juga dikarenakan sifat teripang yang peka terhadap sinar matahari.

Hubungan antara kerapatan lamun dengan kelimpahan teripang di Pantai Alang-alang disajikan pada Gambar 3 dibawah ini. 


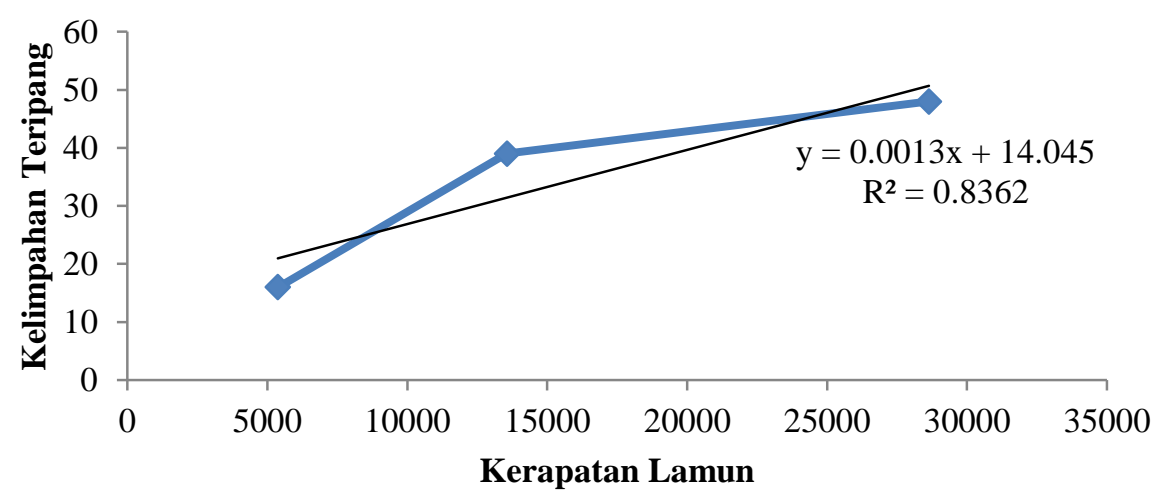

Gambar 3. Hubungan antara Kerapatan Lamun dengan Kelimpahan Teripang

Hubungan antara kerapatan lamun dengan kelimpahan teripang membentuk persamaan $\mathrm{y}=0,001 \mathrm{x}+14,04$. Nilai koefisien korelasi (r) sebesar 0,914 dan koefisien determinasi (R) sebesar 0,836. Hubungan kerapatan lamun dengan kelimpahan teripang pada Pantai Alang-alang dikatakan adanya hubungan yang tinggi. Menurut Arifin (2005) dalam Rukim (2006), bahwa nilai $0,070 \leq \mathrm{r} \leq 1,00$ maka menunjukkan adanya hubungan yang tinggi.

Hubungan antara kerapatan lamun yang berbeda dengan kelimpahan teripang menunjukkan korelasi $\quad r=$ 0,914 menunjukkan derajat asosiasi yang tinggi. Hal tersebut menggambarkan bahwa ada korelasi yang erat antara kerapatan lamun dengan kelimpahan teripang. Nilai determinasi $R^{2}=0,836$ menunjukkan bahwa 83,6\% kerapatan lamun mempengaruhi kelimpahan teripang, 16,4\% sisanya merupakan pengaruh dari faktor-faktor lain. Dapat dikatakan pula bahwa semakin rapat padang lamun, kelimpahan teripang pada padang lamun tersebut juga meningkat. Lamun yang lebat merupakan tempat yang disukai teripang untuk berlindung diri. Padang lamun yang memiliki kerapatan yang padat memungkinkan sebagai tempat perlindungan bagi teripang karena tersedia berbagai macam sumberdaya makanan dan kestabilan lingkungan. Seperti yang diutarakan Rinal (2011) dalam Fasa (2012), bahwa padang lamun juga berfungsi sebagai tempat untuk melindungi diri dari ancaman predator. Teripang juga memiliki fungsi ekologis yang dapat dimanfaatkan lamun untuk pertumbuhan. Pertumbuhan lamun sangat dipengaruhi oleh faktor-faktor seperti fisiologi, metabolisme, zat-zat hara, tingkat kesuburan substrat, dan faktor lingkungan yang lainnya.

Pengukuran parameter kualitas perairan yang dilakukan pada penelitian ini meliputi parameter fisika dan kimia. Parameter fisika yaitu mencakup pengukuran suhu, kedalaman dan kecepatan arus. Sedangkan parameter kimia mencakup pengukuran $\mathrm{pH}$ dan salinitas. Hasil pengukuran dapat dilihat pada Tabel 2 berikut. Tabel 3. Hasil Pengukuran Parameter Kualitas Perairan

\begin{tabular}{lccc}
\hline \multirow{2}{*}{ Parameter } & \multicolumn{3}{c}{ Nilai hasil pengamatan } \\
\cline { 2 - 4 } & Padat (A) & Sedang (B) & Jarang (C) \\
\hline Suhu $(\circ \mathbf{C})$ & 29 & 29 & 29 \\
Salinitas (\%o) & 31 & 31 & 31 \\
pH & 9 & 9 & 9 \\
Kedalaman (cm) & $83-97$ & $61-74$ & $45-58$ \\
Kec. Arus (m/dt) & 0,43 & 0,47 & 0,54 \\
\hline
\end{tabular}

Hasil pengukuran di lapangan selama penelitian, suhu perairan pada Pantai Alang-alang sebesar $29^{\circ} \mathrm{C}$. Saat pengukuran, cuaca memang sedang lumayan mendung. Menurut Elfidasari et al., (2012), bahwa Beberapa peneliti mencatat bahwa teripang mampu bertahan pada temperatur $25-35^{\circ} \mathrm{C}$. Lebih dari $35^{\circ} \mathrm{C}$ tubuh teripang akan mengalami inaktif akan tetapi tentakelnya masih dapat bergerak. Derajat keasaman $(\mathrm{pH})$ air laut yang diperoleh pada ketiga titik sampling termasuk normal dengan nilai $\mathrm{pH}$ pada kerapatan padat, sedang dan jarang yaitu 9. Nilai derajat keasaman yang cukup seragam atau homogen pada ketiga stasiun penelitian, hal tersebut disebabkan karena $\mathrm{pH}$ air laut biasanya tidak menunjukkan perubahan yang cukup besar dan biasanya cukup stabil karena adanya system karbonat dalam air laut (Nybakken, 1992).

Hasil pengukuran salinitas pada kerapatan lamun padat, sedang dan jarang di perairan Pantai Alang-alang yaitu stabil pada angka $31^{\circ}$ oo. Menurut Zieman (1975) dalam Supriharyono (2007), secara umum salinitas yang optimum untuk pertumbuhan lamun berkisar antara 25-35\%. Sementara salinitas yang optimum untuk teripang yaitu antara 3037\%o (Elfidasari et al., 2012). Kedalaman pada kerapatan lamun padat yaitu mencapai 83 - $97 \mathrm{~cm}$. Kedalaman pada lamun dengan kerapatan lamun sedang yaitu mencapai $61-74 \mathrm{~cm}$. Sedangkan kedalaman pada lamun dengan kerapatan jarang yaitu mencapai $45-58 \mathrm{~cm}$. Menurut Kordi (2009), bahwa teripang adalah salah satu hewan yang hidup di perairan pantai, mulai dari daerah pasang surut yang dangkal sampai perairan yang dalam. Beberapa kelompok hidup di daerah berbatu yang dapat digunakan sebagai tempat persembunyian. Sedangkan yang lain hidup pada daerah 
yang ditumbuhi rumput laut, lamun atau daerah berpasir, ada pula yang membuat lubang di lumpur dan pasir. Teripang hidup pada kedalaman $1-40 \mathrm{~m}$.

Kecepatan arus pada lamun dengan kerapatan padat, sedang, dan jarang yaitu berbeda-beda. Kecepatan arus pada lamun dengan kerapatan padat yaitu sebesar 0,43 m/dt. Kecepatan arus pada lamun dengan kerapatan sedang yaitu sebesat 0,47 m/dt. Sedangkan kecepatan arus pada lamun dengan kerapatan jarang yaitu sebesar 0,54 m/dt. Menurut Nybakken (1992), menyatakan bahwa lamun di perairan laut bebas sangat dipengaruhi oleh arus. Arus memiliki banyak keuntungan, salah satunya yaitu membawa nutrisi. Di daerah padang lamun perairan cenderung tenang karena tumbuhan lamun mempunyai sistem perakaran yang padat dan saling menyilang.

\section{KESIMPULAN}

Kesimpulan yang didapatkan berdasarkan hasil penelitian Hubungan Kerapatan Lamun (Seagrass) dengan Kelimpahan Teripang (Holothuria) Pantai Alang-alang Taman Nasional Karimunjawa adalah Kelimpahan teripang di Pantai Alang-alang yaitu kurang beragam, teripang yang ditemukan pada Pantai Alang-alang yaitu hanya satu jenis yaitu Holothuria atra yang dimana pada kerapatan padat ditemukan sebanyak 48 individu/ $240 \mathrm{~m}^{2}$, pada kerapatan lamun sedang ditemukan sebanyak 39 individu $/ 240 \mathrm{~m}^{2}$, sedangkan pada kerapatan lamun jarang hanya ditemukan sebanyak 16 individu $/ 240 \mathrm{~m}^{2}$. Keanekaragaman lamun pada kerapatan padat yaitu 1,358 , pada kerapatan lamun sedang yaitu 1,186, sedangkan pada kerapatan lamun jarang yaitu 1,338. Jenis lamun yang paling mendominasi pada ketiga titik tersebut yaitu jenis Thalassia hemprichii. Hasil analisa statistika menunjukkan nilai korelasi $r=0,914$. Antara kerapatan lamun dengan kelimpahan teripang terdapat korelasi yang erat sehingga semakin tinggi kerapatan lamun akan diikuti oleh tingginya kelimpahan teripang.

\section{UCAPAN TERIMAKASIH}

Penulis mengucapkan terimakasih kepada Dr. Ir. Bambang Sulardiono, M.Si., Ir. Anhar Solichin, M.Si., dan pihak-pihak lain yang banyak memberikan kontribusi dalam penelitian ini.

\section{DAFTAR PUSTAKA}

Bengen, D, G. 2001. Ekologi dan Sumberdaya Pesisir dan Laut serta Pengelolaannya $\quad$ secara Terpadu dan Berkelanjutan. Prosiding Pengelolaan Wilayah Pesisir Terpadu. Bogor 23 Oktober - 3 November 2001. Pusat Kajian Sumberdaya Pesisir dan Lautan (PKSPBL)-IPB.Bogor.

Dahuri, R. 2003. Keanekaragamn Hayati Laut. Aset Pembangunan Berkelanjutan Indonesia. PT Gramedia Pustaka Utama. Jakarta

Elfidasari, D. N., N. Noriko, N. Wulandari, A. T. Perdana. 2012. Identifikasi Jenis Teripang Genus Holothuria Perbedaan Morfologi. Jurnal Al - Azhar Indonesia Seri Sains dan Teknologi 1(3) : 140 - 146

Haryasakti, H. 2011. Frekuensi dan Sebaran Teripang (Holothuroidea) pada Berbagai Mikrohabitat di Pantai Teluk Lombok Kecamatan Sangatta Selatan Kabupaten Kuta Timur Kalimantan Timur. Jurnal Pertanian Terpadu $1(2): 104-113$

Kordi, K. G., A. B. Tancung. 2009. Pengelolaan Kualitas Air dalam Budidaya Perairan. Rineka Cipta : Jakarta

Nybakken. 1992. Biologi Laut Suatu Pendekatan Ekologis. PT. Gramedia. Jakarta.

Odum, E.P. 1971. Fundamental of Ecology. WB Sounders. Toronto. 547 pp

Romimohtarto, K., dan J. Sri. 2001. Biologi Laut Ilmu Pengetahuan tentang Biota Laut. Djambatan : Jakarta

Sudjana. 2002. Metoda Statistika. Tarsito. Bandung

Supriharyono. 2007. Konservasi Ekosistem Sumberdaya Hayati. Pustaka Pelajar : Yogyakarta.

Vermaat, J. E., N. S. R. Agawin, C. M. Duarte. M.D. Fortes.,N. Marba. dan J. S. Uri. 1995. Meadow Maintenance, Growth and Productivity of a Mixed Philippine Seagrass Bed. Marine Ecology Progress Series, 124:215-225.

Widyorini, N., Ruswahyuni, B. Sulardiono, D, Suprapto dan A. Suryanto. 2012. Kajian Kondisi Ekosistem Pulau Panjang untuk Kegiatan Perikanan di Kabupaten Jepara Provinsi Jawa Tengah. Universitas Diponegoro. Semarang

Wilhm, J. K and T.C. Dorris. 1986. Biological Parameter for Water Quality Criteria. $\quad$ Biologi Scientific Publication. Oxford

Yanu, A.U. 2011. Struktur Komunitas Moluska di Padang Lamun Perairan Pulau Talise, Sulawesi Utara. $\quad 37(1)$ : $71-$ 89 